20

\title{
Оптические свойства in vitro катарактальных хрусталиков глаза человека в видимом и ближнем ИК диапазонах*
}

\author{
(C) А.В. Беликов ${ }^{1}$, А.М. Загорулько ${ }^{2}$, С.Н. Смирнов ${ }^{1, \uparrow, ~ А . Н . ~ С е р г е е в ~}{ }^{1}$, \\ А.А. Михайлова ${ }^{3}$, А.А. Шимко ${ }^{3}$ \\ ${ }^{1}$ Университет ИТМО, \\ 197101 Санкт-Петербург, Россия \\ ${ }^{2}$ Санкт-Петербургский филиал МНТК „Микрохирургия глаза“ им. акад. С.Н. Федорова, \\ 192281 Санкт-Петербург, Россия \\ ${ }^{3}$ Санкт-Петербургский государственный университет, ресурсный центр \\ „Оптические и лазерные методы исследования вещества“, \\ 198504 Санкт-Петербург, Россия \\ ฯ e-mail: s.n.smirnov@inbox.ru
}

Поступила в редакцию 08.01.2019 г.

В окончательной редакции 24.01.2019 г.

Принята к публикации 31.01.2019 г.

\begin{abstract}
Исследованы спектральные зависимости коэффициента поглощения, коэффициента рассеяния, фактора анизотропии и транспортного коэффициента рассеяния для хрусталиков глаза человека in vitro с различной стадией катаракты. Спектры коэффициента поглощения и транспортного коэффициента рассеяния получены для спектрального диапазона $400-2300 \mathrm{~nm}$, а спектры коэффициента рассеяния и фактора анизотропии рассеяния - для спектрального диапазона $400-1800 \mathrm{~nm}$. Определены области длин волн, внутри которых спектры исследованных оптических характеристик хрусталика глаза человека статистически значимо не различаются для образцов с различной стадией зрелости катаракты и, наоборот, внутри которых они статистически значимо различаются.
\end{abstract}

DOI: $10.21883 /$ OS.2019.05.47667.16-19

\section{Введение}

Оптимизация светового воздействия с целью диагностики, терапии или хирургии в офтальмологии невозможна без полного знания оптических свойств структур глаза в норме и при патологии. Развитие современных методов энергетической, в том числе лазерной хирургии катаракты, требует детального изучения спектральных зависимостей основных оптических характеристик хрусталика глаза человека с различной стадией катаракты, так как они определяют адекватность выбора параметров лазерного излучения, что является ключевым фактором, ответственным за успех лазерной экстракции катаракты.

Спектральные свойства хрусталика глаза животных и человека в норме и их изменение по мере старения достаточно хорошо изучены. В работе [1] обсуждается спектр поглощения хрусталика обезьяны в норме для диапазона длин волн от $300 \mathrm{~nm}$ до $5 \mu \mathrm{m}$. Оптические свойства хрусталиков глаза быка и человека исследовались в работе [2] для длин волн 980, 1310 и $1530 \mathrm{~nm}$. В работе [3] представлены оптические коэффициенты тканей глаза быка, в том числе хрусталика в норме, в спектральном диапазоне 750-1000 nm. Спектральные

\footnotetext{
* The 22nd Annual Conference Saratov Fall Meeting 2018 (SFM'18): VI International Symposium „Optics and Biophotonics“ and XXII International School for Junior Scientists and Students on Optics, Laser Physics \& Biophotonics, September 24-29, 2018, Saratov, Russia. https://www.sgu.ru/structure/fiz/saratov-fall-meeting/previousconferences/sara
}

зависимости коэффициентов рассеяния и поглощения бычьих хрусталиков в норме были получены в [4] для трех длин волн излучения $\mathrm{Ar}$-лазера (457.9, 488 и $514.5 \mathrm{~nm})$. Спектры коллимированного пропускания хрусталика в диапазоне длин волн $300-1100 \mathrm{~nm}$, рассчитанные для упорядоченных и неупорядоченных рассеивателей представлены в работе [5]. Экспериментальные спектры полного пропускания изолированных возрастного и катарактального хрусталиков в диапазоне длин волн 300-800 nm обсуждаются в работе [6]. В данном случае спектры демонстрируют достаточно близкий характер, поскольку при таком способе измерений изменение рассеивающих свойств ткани зарегистрировать трудно, а изменения в спектрах можно отнести в основном на счет изменения поглощения, которое более сильно проявляется для хрусталика с бурой катарактой [7]. Изменение состава рассеивателей и поглотителей с возрастом приводит к довольно существенным различиям также и в спектрах рассеяния хрусталика [7]. Результаты расчетов для обратного рассеяния и рассеяния под углом $90^{\circ}$ в диапазоне длин волн 300-1100 nm [8] качественно согласуются с экспериментальными данными, представленными в [9].

В литературе также обсуждаются спектры поглощения содержащихся в хрусталике веществ, а также обсуждается влияние изменения концентрации этих веществ в течение жизни на спектр поглощения хрусталика. В работе [10] представлены спектры поглощения 
возрастного белка хрусталика, а также входящего в состав хрусталика триптофана и пигмента О- $\beta$ глюкозид 3-HKG, в том числе показано, что полосы поглощения перечисленных веществ приходятся на УФ и видимую области спектра. В работе [11] обсуждаются спектры поглощения хрусталика обезьяны в норме и хрусталика пожилого человека. Установлено различие в спектрах поглощения, которое объясняется сменой доминирующего хромофора по мере старения вещества хрусталика: в молодых хрусталиках доминирует О- $\beta$ глюкозид 3-HKG, а по мере старения доминирующим хромофором становится возрастной (желтый) белок.

Несмотря на достаточно большое количество спектральных исследований, к сожалению, следует отметить, что поведение основных оптических характеристик (коэффициент поглощения $\left(\mu_{a}\right)$, коэффициент рассеяния $\left(\mu_{s}\right)$, фактор анизотропии $(g)$ и транспортный коэффициент рассеяния $\left.\left(\mu_{s}^{\prime}\right)\right)$ хрусталиков глаза человека с различной стадией созревания катаракты в инфракрасном диапазоне остается не до конца изученным, особенно в ближнем инфракрасном диапазоне, который представляет особый интерес, поскольку излучение лазеров этого спектрального диапазона (Nd:YAG $(\lambda=1.44 \mu \mathrm{m})$ [12], Yb,Er:Glass $(\lambda=1.54 \mu \mathrm{m})$ [13] и фемтосекундные лазеры с $\lambda \approx 1 \mu \mathrm{m}[14])$ широко используется в микрохирургии глаза и весьма перспективно для лазерной экстракции катаракт.

Настоящая работа посвящена исследованию поведения вышеперечисленных оптических коэффициентов хрусталика глаза человека с различной стадией зрелости катаракты в видимом и ближнем инфракрасном диапазонах спектра.

\section{Материалы и методы}

Хрусталики глаза человека для проведения экспериментальных исследований были получены в ходе операции по хирургии катаракты путем экстракапсулярной экстракции. После изъятия из полости глаза хрусталики были помещены в вискоэластик „Визитон-ПЭГ“ (ООО „НЭП МГ“, Россия) и хранились в нем не более одной недели в холодильнике при температуре $\sim 4^{\circ} \mathrm{C}$. Перед подготовкой образцов для спектрофотометрических измерений хрусталики тщательно промывались от остатков вискоэластика. Образцы представляли собой тонкие срезы диаметром $6.5 \pm 0.3 \mathrm{~mm}$, вырезанные из экваториальной части хрусталиков при помощи лезвия бритвы „Gillette Platinum Plus“ (P\&G, США). Образцы были разделены на 3 группы в зависимости от стадии (степени) катаракты, согласно [15]: II стадия (5 образцов), III-IV стадия (8 образцов) и V стадия (5 образцов). Описание подготовленных для спектроскопических исследований образцов хрусталиков приведено в таблице. Фотографии типичных хрусталиков на исследуемых стадиях зрелости катаракты представлены на рис. 1.
Описание образцов хрусталиков глаза человека in vitro для спектрофотометрических исследований

\begin{tabular}{c|c|c}
\hline № образца & Толщина среза, $\mathrm{mm}$ & Стадия зрелости катаракты \\
\hline $1-5$ & $1.55 \pm 0.11$ & $\mathrm{II}$ \\
$6-13$ & $1.24 \pm 0.08$ & $\mathrm{III}-\mathrm{IV}$ \\
$14-18$ & $1.32 \pm 0.13$ & $\mathrm{~V}$
\end{tabular}

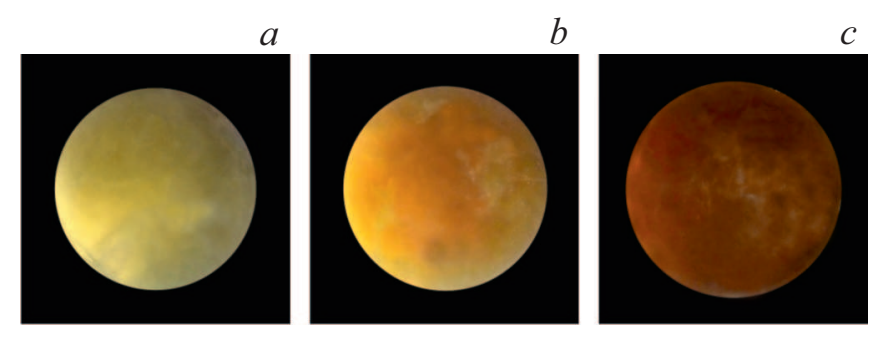

Рис. 1. Фотографии типичных хрусталиков глаза человека in vitro: II $(a)$, III-IV $(b)$ и V $(c)$ стадии катаракты. Размер кадра $12 \times 12 \mathrm{~mm}$.

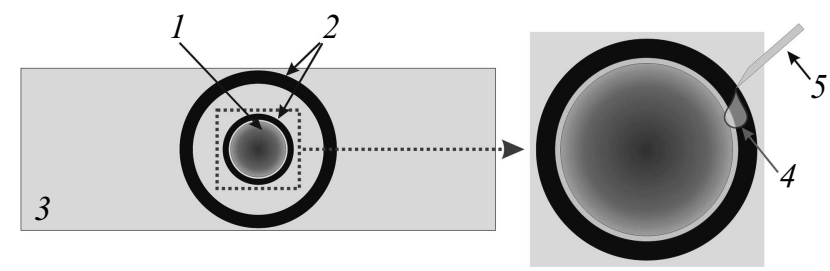

Pис. 2. Схематичное изображение держателя образца: 1 образец (срез хрусталика); 2 - резиновые прокладки (o-rings); 3 - предметное стекло; 4 - физраствор; 5 - инъекционная игла.

Образцы закреплялись в держателе с минимальной компрессией, поскольку она оказывает значительное влияние на оптические свойства исследуемой мягкой биоткани [16]. Держатель представлял собой два предметных стекла (BK7), между которыми располагались резиновые прокладки (o-rings) для поддержки образца и обеспечения его равномерного зажатия (рис. 2). Для предотвращения дегидратации образца во время проведения измерений пространство между резиновой прокладкой и образцом предварительно заполнялось физраствором.

Измерения коэффициентов полного пропускания и диффузного отражения образцов были проведены с использованием спектрофотометра „Lambda 1050“ („Perkin Elmer, Inc.“, США) с интегрирующей сферой диаметром $150 \mathrm{~mm}$. Спектральные зависимости данных коэффициентов были получены в диапазоне длин волн 400-2300 nm. Схемы измерения полного пропускания и диффузного отражения показаны на рис. 3, $a$ и $b$ соответственно. Размер падающего на образец пучка света в этих схемах ограничивался диафрагмой 2 и составлял $3.0 \pm 0.1 \mathrm{~mm}$. 


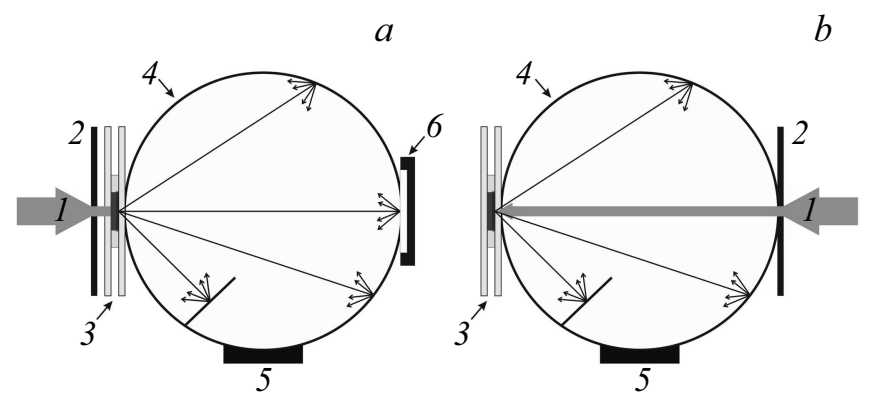

Рис. 3. Схема измерения полного пропускания $(a)$ и диффузного отражения $(b): 1$ - пучок света; 2 - круглая диафрагма (диаметр $3 \mathrm{~mm}$ ); 3 - образец в держателе; 4 интегрирующая сфера; 5 - фотодетектор; 6 - эталонный рассеиватель.

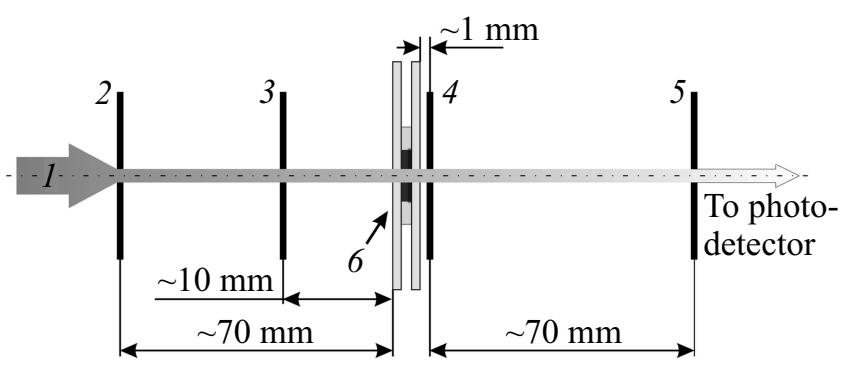

Рис. 4. Схема диафрагмирования пучка при измерении коллимированного пропускания: $1-$ пучок света; $2-5-$ круглые диафрагмы (диаметр $2 \mathrm{~mm}$ ); 6 - образец в держателе.

Коллимированное пропускание образцов измерялось также с использованием спектрофотометра „Lambda 1050“ („Perkin Elmer, Inc.“, США), но вместо интегрирующей сферы в измерительный канал устанавливалась система диафрагм. Измерение коллимированного пропускания проводилось в диапазоне 400-1800 nm. Схема измерения коллимированного пропускания показана на рис. 4. Размер падающего на образец пучка света в этом случае составлял $2.0 \pm 0.1 \mathrm{~mm}$.

Выбор диапазонов длин волн был обусловлен высоким отношением сигнал/шум и, как следствие, сравнительно малой погрешностью измерений. При измерениях в диапазоне 400-850 nm использовался стандартный фотоэлектронный умножитель, а ширина щели составляла $2 \mathrm{~nm}$. При измерениях в диапазоне 850-2300 nm использовался стандартный InGaAs-детектор и был установлен режим „Servo“, подбирающий ширину щели автоматически в зависимости от сигнала на детекторе. Сканирование осуществлялось с шагом $2 \mathrm{~nm}$.

Все спектральные измерения проводились в центральной области образцов, при этом смещение пучка от центра образца не превышало $0.2 \mathrm{~mm}$. Для каждого образца было выполнено по 10 измерений.

Полученные при помощи спектрофотометрических измерений коэффициенты диффузного отражения $\left(R_{d}\right)$, а также коэффициенты полного $\left(T_{t}\right)$ и коллимированного
$\left(T_{c m}\right)$ пропускания образцов представляли собой начальный набор данных для дальнейшего анализа. На следующем этапе данные обрабатывались в программе „IAD“ [https://omlc.org/software/iad/], реализующей итерационный инверсный метод ,добавления-удвоения“(ИДУ) [17] для решения обратной задачи переноса излучения. Метод ИДУ успешно применяется для обработки данных спектрофотометрических измерений с использованием интегрирующих сфер [18-20], а результаты вычисления при таком подходе не зависят от соотношения между собой коэффициентов поглощения и рассеяния образца [17]. Поскольку соотношение коэффициентов поглощения и рассеяния катарактальных хрусталиков с различной стадией катаракты в широком диапазоне длин волн неизвестно, метод ИДУ лучше всего подходит для обработки результатов.

В результате обработки программа „IAD“ формирует спектральные зависимости коэффициента поглощения $\left(\mu_{a}\right)$ и транспортного коэффициента рассеяния $\left(\mu_{s}^{\prime}\right)$ образцов. Транспортный коэффициент рассеяния определяется следующим соотношением:

$$
\mu_{s}^{\prime}=\mu_{s}(1-g)
$$

где $\mu_{s}^{\prime}$ - коэффициент рассеяния, $g$ - фактор анизотропии рассеяния.

При расчете $\mu_{a}$ и $\mu_{s}^{\prime}$ при помощи метода ИДУ фактор анизотропии рассеяния был принят равным $g=0.8$, что характерно для большинства биологических тканей в видимой и ближнем инфракрасном диапазонах [21]. Показатель преломления $n$ хрусталика был принят равным 1.4 [3,4].

В эксперименте диаметр исследуемого образца существенно превышал размеры падающего на его поверхность светового пучка. Это позволило избежать ошибок в определении оптических коэффициентов, которые могли появиться за счет потерь рассеянного излучения через боковые стороны образца [22].

Фактор анизотропии рассеяния $g$ вычислялся на основе измеренного коэффициента коллимированного пропускания $T_{c m}$, а также полученных на предыдущем этапе коэффициентов $\mu_{a}$ и $\mu_{s}^{\prime}$. Согласно закону БугераЛамберта-Бера, коэффициент коллимированного пропускания $T_{c}$ определяется следующим образом:

$$
T_{c}=\exp \left(-\mu_{t} l\right)=\exp \left(-\left(\mu_{a}+\mu_{s}\right) l\right) \text {, }
$$

где $\mu_{t}$ - коэффициент экстинкции, $l-$ толщина среза (образца), $\mu_{s}$ - коэффициент рассеяния, $\mu_{a}$ - коэффициент поглощения.

Для получения коэффициента коллимированного пропускания образца $T_{c}$ необходима корректировка измеренного коэффициента коллимированного пропускания $T_{c m}$, т.е. необходимо учесть потери, связанные с отражением света на поверхностях стекол, между которыми был закреплен образец. Суммарный коэффициент отражения для системы воздух-стекло-воздух может 
быть оценен как [23]

$$
R=\frac{R_{a g}+R_{g s}-2 R_{a g} R_{g s}}{1-R_{a g} R_{g s}},
$$

где $R_{a g}-$ коэффициент френелевского отражения на границе воздух-стекло, $R_{g s}$ - коэффициент френелевского отражения на границе стекло-образец.

В таком случае измеренный коэффициент пропускания $T_{c m}$ связан с коэффициентом коллимированного пропускания образца $T_{c}$ следующим выражением [23]:

$$
T_{c m}=\frac{(1-R)^{2} T_{c}}{1-R^{2} T_{c}^{2}} .
$$

Отсюда коэффициент $T_{c}$ может быть выражен как

$$
T_{c}=\frac{-(1-R)^{2}-\sqrt{(1-R)^{4}+4 R^{2} T_{c m}^{2}}}{2 T_{c m} R^{2}} .
$$

Исходя из (1) и (2) для фактора анизотропии рассеяния образца имеем следующее выражение:

$$
g=\frac{\mu_{s}^{\prime}}{\frac{\ln \left(T_{c}\right)}{l}+\mu_{a}}+1 .
$$

Для статистической обработки полученных данных использовался программный пакет „StatGraphics Plus“ (Statgraphics Technologies, Inc., США). Для коэффициента поглощения $\left(\mu_{a}\right)$, коэффициента рассеяния $\left(\mu_{s}\right)$, фактора анизотропии $(g)$ и транспортного коэффициента рассеяния $\left(\mu_{s}^{\prime}\right)$ хрусталиков вычислялись среднее и доверительный интервал для каждого значения длины волны спектра. Сравнение спектров вышеперечисленных оптических коэффициентов, полученных для катарактальных хрусталиков с различной стадией катаракты между собой на предмет их статистически значимого различия, проводилось по тесту КолмогороваСмирнова.

\section{Результаты и обсуждение}

Рассчитанные при помощи метода ИДУ спектральные зависимости коэффициента поглощения $\left(\mu_{a}\right)$ и транспортного коэффициента рассеяния $\left(\mu_{s}^{\prime}\right)$ образцов хрусталика глаза человека с различной стадией катаракты представлены на рис. 5.

При сравнении спектральных зависимостей коэффициента поглощения образцов катарактальных хрусталиков II и III-IV стадий тест Колмогорова-Смирнова показал, что во всем исследованном спектральном диапазоне, за исключением $\lambda=2100-2125$ нм, эти спектры статистически значимо отличаются друг от друга $(p<0.05)$. При сравнении спектров поглощения образцов катарактальных хрусталиков II и V стадий статистически значимое отличие наблюдается также во всем диапазоне длин волн, за исключением области $\lambda=1400-1500 \mathrm{~nm}$, a при сравнении III-IV и V стадий - за исключением $\lambda=760-785 \mathrm{~nm}$ и $1855-1890 \mathrm{~nm}$.

При сравнении спектральных зависимостей транспортного коэффициента рассеяния образцов катарактальных хрусталиков II и III-IV стадий тест Колмогорова-Смирнова показал, что во всем исследованном спектральном диапазоне, за исключением $\lambda=2100-2125 \mathrm{~nm}$, эти спектры статистически значимо отличаются друг от друга $(p<0.05)$. При сравнении спектров транспортного коэффициента рассеяния образцов катарактальных хрусталиков II и V стадий статистически значимое отличие наблюдается также во всем диапазоне длин волн, за исключением $\lambda=1385-1395$, $1530-1570,1770-1850,2100-2300 \mathrm{~nm}$, а при сравнении III-IV и V стадий - за исключением $\lambda=590-620$ и $2270-2300 \mathrm{~nm}$.

Спектр поглощения катарактального хрусталика в видимой области в основном определяется пигментами, которые получаются из аминокислоты триптофан и накапливаются с возрастом и при катаракте [2426]. В ближней ИК области спектр поглощения хрусталика определяется содержащейся в нем свободной и связанной водой - пики поглощения в окрестностях 1450 и $1950 \mathrm{~nm}$. В работе [27] отмечено отсутствие значительного изменения содержания воды в ядре хрусталиков человека при изменении возраста от 13 до 82 лет, что может быть не связано с катарактой. При катаракте ядро хрусталика уплотняется, а содержание связанной воды в нем уменьшается $[27,28]$. В диапазоне $1900-2100 \mathrm{~nm}$ наблюдается искажение спектров, связанное с практически нулевым пропусканием образцов, что обусловливает низкое значение соотношения сигналшум. Стоит отметить высокие значения транспортного коэффициента рассеяния $\left(\mu_{s}^{\prime}\right)$ как в видимой, так и в ближней ИК областях спектра. Появление максимумов в спектрах $\mu_{s}^{\prime}$ в ближней ИК области, где находятся полосы интенсивного поглощения воды, наблюдалось также в [18]. Согласно [18], подобный эффект может быть связан с ростом мнимой части показателя преломления рассеивателей и базового вещества, приводящим к значительному уменьшению фактора анизотропии рассеяния $g$, который, в частности, определяет транспортный коэффициент рассеяния.

Рассчитанные на основе выражений (1) и (6) спектральные зависимости коэффициента рассеяния $\left(\mu_{s}\right)$ и фактора анизотропии рассеяния $(g)$ образцов хрусталика глаза человека с различной стадией катаракты представлены на рис. 6.

Искажение спектров в области $850-980 \mathrm{~nm}$ может быть связано с переключением датчиков: при $\lambda \leq 850 \mathrm{~nm}$ регистрация сигнала осуществлялась при помощи $Ф Э У$, а при $\lambda>850 \mathrm{~nm}$ - при помощи InGaAs фотоприемника.

При сравнении спектральных зависимостей коэффициента рассеяния катарактальных хрусталиков II и III-IV стадий тест Колмогорова-Смирнова показал, что 

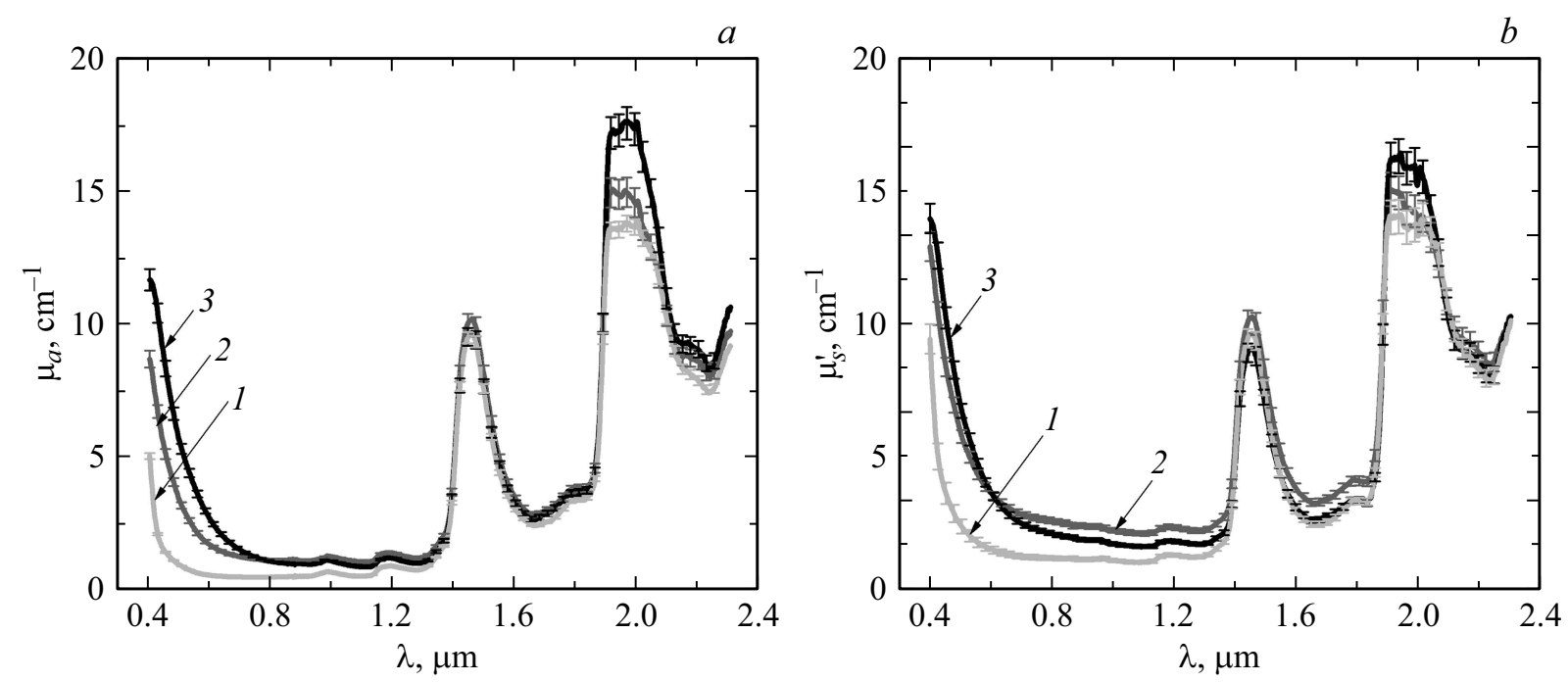

Рис. 5. Спектральные зависимости коэффициента поглощения $\mu_{a}(a)$ и транспортного коэффициента рассеяния $\mu_{s}^{\prime}(b)$ образцов хрусталика глаза человека in vitro с различной стадией катаракты: 1 - II стадия, 2 - III-IV стадия, 3 - V стадия.
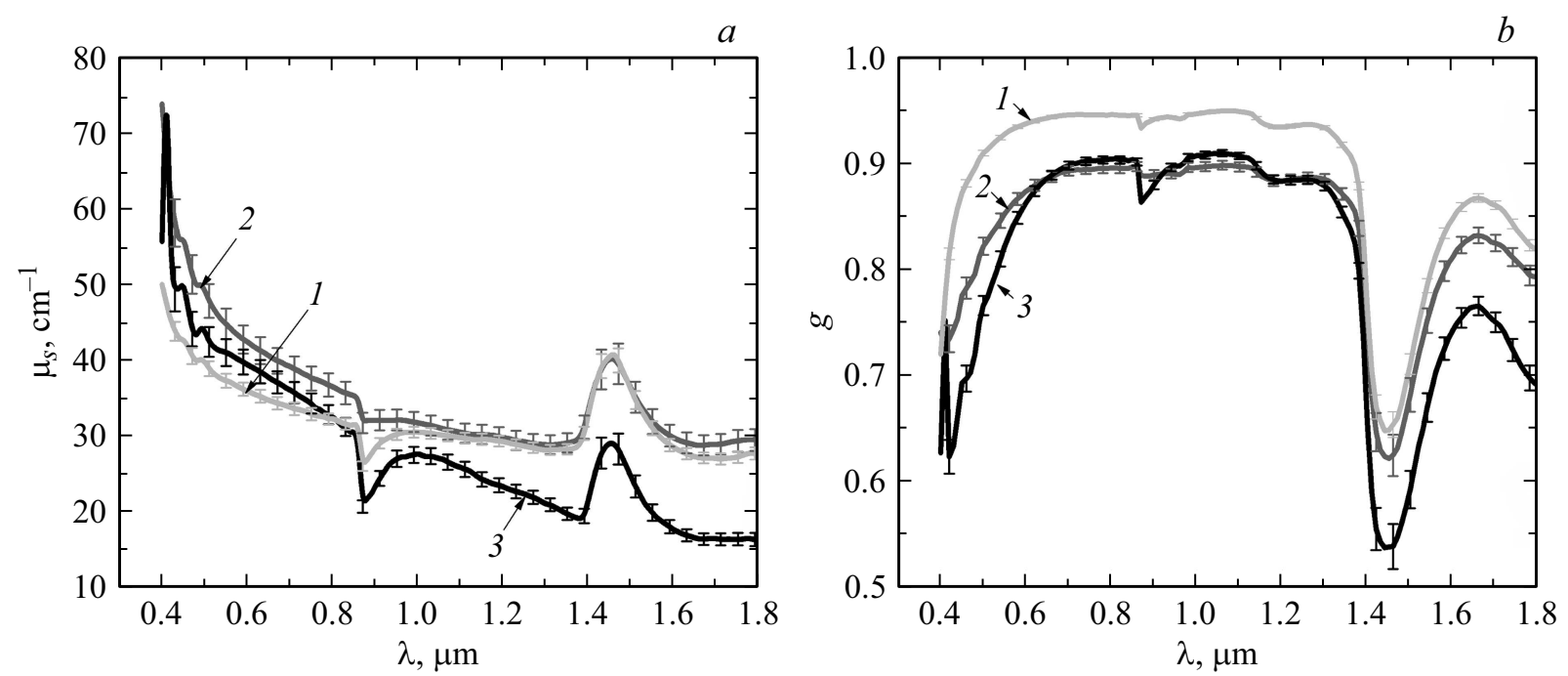

Рис. 6. Спектральные зависимости коэффициента рассеяния $\mu_{s}(a)$ и фактора анизотропии рассеяния $g(b)$ образцов хрусталика глаза человека in vitro с различной стадией катаракты: 1 - II стадия, 2 - III-IV стадия, 3 - V стадия.

во всем исследованном спектральном диапазоне, за исключением области $1410-1520 \mathrm{~nm}$, эти спектры статистически значимо отличаются друг от друга $(p<0.05)$. Спектральные зависимости коэффициента рассеяния катарактальных хрусталиков III-IV и V стадий статистически значимо отличаются друг от друга $(p<0.05)$ во всем исследованном диапазоне. При сравнении спектров поглощения катарактальных хрусталиков II и $\mathrm{V}$ стадий статистически значимое отличие наблюдается также во всем диапазоне длин волн, за исключением $\lambda=780-830 \mathrm{~nm}$.

При сравнении спектральных зависимостей фактора анизотропии образцов катарактальных хрусталиков II и III-IV стадий, а также при сравнении II и V стадий тест Колмогорова-Смирнова показал, что во всем исследован- ном спектральном диапазоне эти спектры статистически значимо отличаются друг от друга $(p<0.05)$. При сравнении спектров поглощения фактора анизотропии образцов катарактальных хрусталиков III-IV и V стадий статистически значимое отличие наблюдается также во всем диапазоне длин волн, за исключением $\lambda=630-680$ и $1160-1280 \mathrm{~nm}$.

Увеличение коэффициента рассеяния при переходе от II стадии катаракты к V стадии может быть связано с уплотнением ядра. Повышение жесткости ядра с возрастом отмечалось в работах [28,29]. Авторы работы [30] связывают уплотнение ядра с появлением новых волокон хрусталика на протяжении всей жизни, в результате чего старые волокна сжимаются в центре, а также с увеличением количества агрегированных нерастворимых 
белков. В исследованном диапазоне $(400-1800 \mathrm{~nm})$ зависимость коэффициента рассеяния от длины волны не была монотонно убывающей, а имела максимум в области полосы поглощения воды с центром около $1450 \mathrm{~nm}$. Подобное явление также отмечалось в [31], где объяснялось ростом влияния комплексной части показателя преломления рассеивающих центров.

\section{Заключение}

Изучены оптические свойства хрусталиков глаза человека с различной стадией зрелости катаракты. Получены спектральные зависимости коэффициента поглощения $\left(\mu_{a}\right)$ и транспортного коэффициента рассеяния $\left(\mu_{s}^{\prime}\right)$ в диапазоне 400-2300 nm, а также фактора анизотропии рассеяния $(g)$ и коэффициента рассеяния $\left(\mu_{s}\right)$ (в диапазоне 400-1800 nm) для центральной части катарактальных хрусталиков глаза человека. Установлено, что при изменении стадии катаракты от II к III-IV, а затем к V стадии спектры вышеперечисленных оптических коэффициентов хрусталика статистически значимо изменяются, что необходимо учитывать при разработке новых методов диагностики, профилактики и лечение катаракты. Благодарности

\section{Благодарности}

Все измерения были проведены в ресурсном центре „Оптические и лазерные методы исследования вещества“ Санкт-Петербургского государственного университета.

\section{Соблюдение этических норм}

Все исследования и процедуры с участием людей, соответствуют этическим стандартам Хельсинкской декларации 1964 г. и ее последующим изменениям или сопоставимым нормам этики. От каждого из включенных в исследование участников было получено информированное добровольное согласие.

\section{Конфликт интересов}

Авторы заявляют, что у них нет конфликта интересов.

\section{Список литературы}

[1] Maher E.F. // USAF School of Aerospace Medicine. 1978. Report SAM-TR-78-32.

[2] Sardar D.K., Yow R.M., Swanland G.-Y., Thomas R.J., Tsin A.T.C. // Proc. SPIE. 2006. V. 6138. P. 613815.

[3] Yust B.G., Mimun L.C., Sardar D.K. // Lasers Med Sci. 2012. V. 27. N 2. P. 413-422.

[4] Sardar D.K., Yust B.G., Barrera F.J., Mimun L.C., Tsin A.T.C. Lasers Med Sci. 2009. V. 24. N 6. P. 839-847.
[5] Tuchin V.V., Maksimova I.L., Kochubey V.I., Semenova T.N., Tatarintsev S.N., Babkova N.L. // Proc. SPIE. 1995. V. 2393. P. 237-253.

[6] Tuchin V.V., Maksimova I.L., Yaroslavskaya A.N., Semenova T.N., Tatarintsev S.N., Kochubey V.I., Isotova V.F. // Proc. SPIE. 1994. V. 2126. P. 393-406.

[7] Тучин В.В. Лазеры и волоконная оптика в биомедицинских исследованиях. 2-е изд., испр. и доп. М.: Физматлит, 2010. $488 \mathrm{c}$.

[8] Tuchin V.V., Zhestkov D.M. // Proc. SPIE. 1997. V. 3053. P. $123-128$.

[9] Zigman S., Sutliff G., Rounds M. // Lens Eye Toxicity Res. 1991. V. 8. P. 259-280.

[10] Dillon J. // J. Photochem. Photobiol. B: Biol. 1991. V. 10. N 1-2. P. 23-40.

[11] Gaillard E.R., Zheng L., Merriam J.C., Dillon J. // Investigative Ophthalmology \& Visual Science. 2000. V. 41. N 6. P. 1454-1459.

[12] Копаев С. Ю., Малюгин Б. Э., Копаева В.Г. // Офтальмохирургия. 2014. № 4. С. 22-28.

[13] Беликов А.В., Гагарский С. В., Губин А.Б., Вайнер С.Я., Сергеев А.Н., Смирнов С.Н. // Научно-технический вестник информационных технологий, механики и оптики. 2015. T. 15. № 6. C. 1021-1029.

[14] Donaldson K.E., Braga-Mele R., Cabot F., Davidson R., Dhaliwal D.K., Hamilton R., Jackson M., Patterson L., Stonecipher K., Yoo S.H. // J. Cataract. Refract. Surg. 2013. V. 39. P. 1753-1763.

[15] Buratto L. Phacoemulsification: Principles and Techniques. SLACK Incorporated, 2003. $768 \mathrm{p}$.

[16] Chan E. K., Sorg B., Protsenko D., O'Neil M., Motamedi M., Welch A.J. // IEEE J. Sel. Top. Quant. Electron. 1996. V. 2. N 4. P. 943-950.

[17] Prahl S.A., Van Gemert M.J.C., Welch A.J. // Appl. Opt. 1993. V. 32. N 4. P. 559-568.

[18] Bashkatov A.N., Genina E.A., Kochubey V.I., Tuchin V.V. // J. Phys. D: Appl. Phys. 2005. V. 38. P. 2543-2555.

[19] Башкатов А.Н., Генина Э.А., Кочубей В.И., Тучин В.В. // Опт. и спектр. 2010. Т. 109. № 2. С. 226-234; Bashkatov A.N., Genina E.A., Kochubey V.I., Tuchin V.V. // Opt. Spectrosc. 2010. V. 109. Iss. 2. P. 197-204.

[20] Башкатов А.Н., Генина Э.А., Козинщева М.Д., Кочубей В.И., Городков С.Ю., Тучин В.В. // Опт. и спектр. 2010. T. 120. № 1. C. 6-14; Bashkatov A.N., Genina E.A, Kozintseva M.D., Kochubei V.I., Gorodkov S.Yu., Tuchin V.V. // Opt. Spectrosc. 2016. V. 120. Iss. 1. P. 1-8.

[21] Tuchin V.V. Tissue Optics: Light scattering methods and instruments for medical diagnosis. SPIE Press, 2007. 882 p.

[22] Pickering J.W., Prahl S.A., van Wieringen N., Beek J.F., Sterenborg H.J.C.M., van Gemert M.J.C. // Appl. Opt. 1993. V. 32. N 4. P. 399-410.

[23] Кочубей В.И., Башкатов А.Н. Спектроскопия рассеивающих сред. Саратов: Новый ветер, 2014. 91 с.

[24] Simunovic M.P. // Arch Ophthalmol. 2012. V. 130. N 7. P. 919-926.

[25] Lerman S. // J. Gerontology. 1983. V. 38. N 3. P. 293-301.

[26] Sen A.C., Ueno N., Chakrabarti B. // Photochemistry and Photobiology. 1992. V. 55. N 5. P. 753-764.

[27] Pescosolido N., Barbato A., Giannotti R., Komaiha C., Lenarduzzi F. // Int J Ophthalmol. 2016. V. 9. N 10. P. 1506-1517. 
[28] Heys K.R. Changes to stiffness and water in the human lens with aging and cataract. $\mathrm{PhD}$ thesis. University of Wollongong, 2010. $133 \mathrm{p}$.

[29] Heys K.R., Cram S.L., Truscott R. J. // Molecular Vision. 2004. V. 16. N 10. P. 956-963.

[30] Tabandeh H., Thompson G. M., Heyworth P. // Eye. 1994. V. 8. P. 453-455.

[31] Башкатов А.Н., Генина Э.А., Кочубей В.И., Рубцов В.С., Колесникова Е.А., Тучин В.В. // Квантовая электроника. 2014. T. 44. № 8. C. 779-784; Bashkatov A.N., Genina E.A., Kochubey V.I., Rubtsov V.S., Kolesnikova E.A., Tuchin V.V. // Quantum Electronics. 2014. V. 44. N 8. P. 779-784. 